\title{
Regionalismo, Liberalismo y Rebelión. Copiapó en la Guerra Civil de 1859
}

\author{
Joaquín Fernández Abara
}

\author{
Santiago de Chile: Escuela de Historia Universidad Finis Terrae, \\ RIL Editores, 2016, 317 páginas
}

Chile, desde que se constituye como una República independiente y tras las primeras luchas en torno a la forma que debía tener el Estado, se caracterizó por un fuerte presidencialismo y el predominio de la ciudad de Santiago sobre otras localidades del país. A pesar de que en algunos periodos históricos el eje del poder institucional y territorial pretendió moverse, esta situación se ha mantenido hasta nuestros días. En el año 2016, se inició en nuestro país un proceso de discusión sobre el cambio constitucional, reflotando con fuerza entre los participantes, la idea de una asamblea constituyente, la necesidad de descentralizar y avanzar en una regionalización auténtica. ${ }^{1}$ Esta mirada evidenció una latente percepción de postergación de las regiones, por una institucionalidad que favorecería a la zona central, particularmente a Santiago.

Ese mismo año, el historiador Joaquín Fernández Abara publica el libro que comentamos, donde analiza un momento de inflexión del Chile decimonónico y que la historiografía no ha abordado en profundidad: el reclamo regionalista contra el Ejecutivo (asentado en Santiago), que se expresó en el levantamiento copiapino de 1859. El texto, de 317 páginas, secuenciadas en una introducción, cuatro capítulos, más las conclusiones, bibliografía y un anexo documental, recoge las investigaciones de Fernández desarrolladas en la última década en torno a esta problemática y amparadas en su tesis de magíster en la Universidad Católica.

El autor, en la introducción, muestra su interés por enfrentar la falta de un enfoque regionalista a la problemática, buscando "dar cuenta de las formas que adquirió el regionalismo en Copiapó y analizar su influencia en la génesis y el desarrollo de la guerra civil de 1859" (p. 24). Para ello, cree "necesario adoptar un esquema que tome en cuenta la relevancia de los factores institucionales, analizándolo en un ámbito local. Esto implica abordar los marcos institucionales en los que se desarrolla el conflicto y

1 En la sistematización de dicho proceso, la descentralización aparece siempre dentro de las prioridades de los participantes. El informe está disponible en: http://www.sistematizacionconstitucional.cl/app/themes/cs/dist/docs/informe_ejecutivo.pdf 
las instituciones que los rebeldes pretendían defender y reformar" (p. 33). Fernández, sostiene como tesis que "el regionalismo en el levantamiento copiapino de 1859, se expresó a través de la defensa de la autonomía de los municipios y de otras corporaciones locales de carácter informal, como era el caso de la Junta de Minería" (p. 34). En este sentido, "la defensa de la autonomía de los municipios y de otras instituciones locales informales de carácter corporativo, como era el caso de la Junta de Minería, fue vista por sus protagonistas como un aspecto más de la lucha por reducir el poder del ejecutivo, y la pugna contra el centralismo como parte de la lucha contra el autoritarismo presidencial" (pp. 35-36).

El análisis institucional local desde donde se enfoca la investigación, abre una veta novedosa para el estudio regional de Copiapó, pues amplía los bordes de lo que se había pesquisado en los últimos años: estudios económicos (Venegas, 2008; Méndez, 2004; Illanes, 2003), de elites (Fernández, 2014; Molina, 2009; Stuven, 2000), políticos (Fernández, 2015; Villalobos, 2009; Rubio, 2008; Bahamondes, 2003), y posibilita complejizar el estudio, lo que hace que la obra no se termine en esta zona minera, sino que el modelo propuesto puede potencialmente ser utilizado en otras investigaciones acerca del regionalismo.

De los cuatro apartados que conforman la investigación, quizás el capítulo segundo, titulado "Crisis Minera y Conflicto Regionalista", y el cuarto, centrado en la "Guerra Civil y Autonomismo Regional" son los medulares, pues en ellos aborda la conformación de la oposición copiapina y cómo se reivindican espacios locales de representación y poder: la Junta de Minería y el Municipio, que para el autor encarnaron las trincheras desde donde se combatió institucionalmente al Ejecutivo y a la Constitución de 1833. En el capítulo cuarto, profundiza en lo que denomina liberalismo contractualista con tradición política municipal, que desarrollaron los rebeldes. Estas instancias locales, según Fernández, fueron asumidas como los depositarios de la voluntad popular, tras desconocer al gobierno de Manuel Montt y a la institucionalidad vigente.

En este capítulo, también, se estudia cómo en pleno auge del conflicto, las elites mineras desplazaron a los sectores medios que abogaban por un liberalismo democratizante y plebeyo, concentrando el poder las ricas familias copiapinas, como los Gallo, las que propiciaron el liderazgo caudillista de Pedro León Gallo, haciendo transformar los propósitos originarios contra el autoritarismo presidencial en un liberalismo corporativista regional.

Por otro lado, la investigación refuerza la convicción sobre la dificultad que tuvo el Estado de instalarse y administrar el territorio en el siglo XIX, debiendo apoyarse en las elites locales para poder asegurar sus tareas. Al respecto, las familias ricas de Copiapó, empoderadas por el rol político, social, económico, e incluso cultural que arrastraban desde la colonia, mantuvieron 
cercanía con las administraciones conservadoras en las primeras décadas del Chile republicano, replicando en la ciudad lo que el centro político definía. Esto se mantuvo hasta que la crisis económica de 1855 afectó sus intereses y las familias notables comienzan a distanciarse del gobierno, en un contexto en que las ideas liberales permearon su grupo y cautivaron a sus generaciones más jóvenes, las que tenían presencia en la Junta de Minería, en el Municipio y en el Congreso Nacional. Este escenario generó críticas al intervencionismo autoritario del gobierno, posibilitando desconocer la institucionalidad que les era adversa y luego levantarse en armas contra el Ejecutivo.

Si bien Fernández trabaja con bastante profundidad y con variadas fuentes los sectores prominentes de la minería, y realiza un esfuerzo similar para estudiar a los sectores mesocráticos (artesanos y pequeños mineros), se extraña la ausencia de los sectores populares, que tuvieron importante presencia en la zona. Al respecto, el autor reconoce esta situación, indicando que no se han encontrado suficientes fuentes para incluirlos (pp. 218-219). Por ello, el abordaje de los sectores populares puede quedar como desafío para próximas investigaciones.

La obra se circunscribe en dos vertientes de plena vigencia en la historiografía contemporánea: los estudios regionales y la nueva historia política. Al circunscribir su análisis en la zona minera de Copiapó, logra con gran habilidad explicar las características del lugar, dando cuenta de la excepcionalidad que representó en varios aspectos la frontera norte que hasta ese momento tenía Chile y que posibilitó el levantamiento copiapino. Además, analiza los conflictos políticos intraelitarios, devenidos tras la crisis económica que con fuerza afectó la zona y que hacen a prominentes familias mineras abrazar un liberalismo contractualista con tradición corporativista local, que pretende cesar, vía levantamiento armado, la Constitución de 1833.

Fernández logra con buena pluma y debidamente documentado, dilucidar las causas que estimularon el alzamiento, los agentes que intervinieron, el movimiento de las familias notables de la zona minera, las correlaciones de fuerzas internas, las tensiones por el poder local y el despliegue en el campo de batalla de las fuerzas en conflicto, situación que permite analizar el proceso en su magnitud, y a la vez, entusiasma al lector, por ser un relato ameno.

Definitivamente, estamos en presencia de una sólida contribución al estudio regional.

Jorge Molina Jara²

2 Chileno. Profesor de Historia y Geografía, Magíster en Historia, Académico de la Universidad Católica del Maule. E-mail: jmolina@ucm.cl 


\title{
Referencias bibliográficas
}

\author{
a) Artículos
}

Fernández, J. (2015). "Guerra, militarización y caudillismo en el norte chileno: el caso de Copiapó en la Guerra Civil de 1859", en Economía y Política, Santiago, N², Vol. 2.

Fernández, J. (2014). "Entre notables y la "gente media": una mirada a la composición social del movimiento opositor copiapino en la antesala de la Guerra Civil de 1859", en C. Donoso y P. Rubio (eds.) Conflictos y tensiones en el Chile republicano. Santiago: RIL Editores, Universidad Andrés Bello.

Illanes, M. A. (2003). "Productores y prestamistas en la minería de Atacama. Una dominación silenciosa", en M. A. Illanes, Chile descentrado. Formación sociocultural republicana y transición capitalista (1810-1910). Santiago: Lom.

Molina, J. (2009). "La familia Gallo de Copiapó y su poder durante la primera mitad del siglo XIX", en Tiempo y Espacio, Chillán, Vol. 22.

Rubio, P. (2008). "¿De revolucionario a moderado? Manuel Antonio Matta y su influencia en la política chilena, 1859-1892", en Revista de Historia y Geografía, Santiago, $N^{\circ} 22$.

\section{b) Libros}

Bahamondes, M. (2003). El Caudillo de Copiapó. Santiago: Ediciones Santos Ossa.

Méndez, L. M. (2004). La exportación minera en Chile. 1800-1840. Un estudio de historia económica y social en la transición de la colonia a la república. Santiago: Editorial Universitaria.

Stuven, A. M. (2000). La seducción de un orden. Las elites y la construcción de Chile en las polémicas culturales y políticas del siglo XIX. Santiago: Ediciones Universidad Católica de Chile.

Venegas, H. (2008). El espejismo de la plata. Trabajadores y empresarios mineros en una economía en transición. Atacama. 1830-1870. Santiago: Ediciones USACH.

Villalobos, S. (2009). Pedro León Gallo. Minería y Política. Santiago: Fundación Tierra Amarilla. 